\title{
Infrared Photography: Untuk Pemasyarakatan Arkeologi
}

\section{Sugeng Riyanto}

Keywords: public archaeology, documentation, photography, techniques, practices, media

\section{How to Cite:}

Riyanto, S. (2006). Infrared Photography: Untuk Pemasyarakatan Arkeologi. Berkala Arkeologi, 26(2), 1-12. https://doi.org/10.30883/jba.v26i2.930

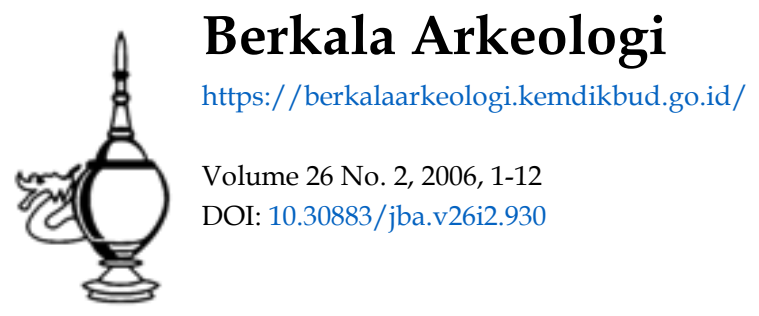

\section{c) (i) (5)}

This work is licensed under a Creative Commons Attribution-NonCommercial-ShareAlike 4.0 International License. 


\title{
INFRARED PHOTOGRAPHY: UNTUK PEMASYARAKATAN ARKEOLOGI
}

\author{
Sugeng Riyanto
}

\section{PENDIDIKAN PUBLIKALAARKEOLOGI: Mereka Menunggu}

Iseminger (1997) menguraikan tentang pengelolaan arkeologi publik di Cahokia, Meksiko dengan penekanan pada pendidikan untuk publik. Dalam hal ini, dia membuat penjenjangan minat publik terhadap masa lalu yang meliputi (Iseminger, 1997: 148-149):

1) arkeolog dan antropolog profesional

2) arkeolog amatir atau pehobi

3) kolektor

4) kalangan akademik di luar disiplin arkeologi maupun antropologi

5) wisatawan yang menaruh minat pada kebudayaan, sejarah, maupun alam

6) masyarakat umum maupun masyarakat lokal

7) kalangan pendidikan

8) siswa

Dijelaskan juga bahwa dalam mempresentasikan informasi kepada publik, digunakan beberapa media yang bervariasi, yang meliputi artefak; model dan diorama antara lain dengan menggunakan mannequin, karya seni dari para seniman dalam bentuk gambar, lukisan, maupun karya grafis; audio-visual dengan menampilkan sejumlah slideshow dan video (disc) yang menggambarkan proses penelitian; teks dan label yang terdiri atas teks pengantar hingga teks detail; dan pameran temporer yang dirancang pada ruang khusus (Iseminger, 1997: 150151).

Dalam arekologi publik, presentasi dapat dilakukan melalui beberapa cara dan media, antara lain melalui display. Berkaitan dengan hal tersebut, Carman (2002: 199-122) menguraikan tentang bentuk-bentuk display, tujuan dan 'gaya' display, 
serta makna dan pesan arkeologis yang dimuat dalam display tersebut, sebagaimana uraian berikut ini.

Bentuk display atau pameran meliputi:

1) pameran temporal, yaitu pameran yang dibatasi oleh durasi waktu tertentu, baik untuk sebagian atau keseluruhan koleksi atau objek

2) pameran permanen, pada prinsipnya juga dibatasi oleh waktu, tetapi dengan durasi yang jauh lebih panjang, misalnya sebagai bagian inti pada sebuah museum

3) pameran pinjaman, pemajangan item tertentu yang dipinjam dari lembaga atau pihak lainnya

4) pameran khusus, bentuk ini misalnya dengan cara memamerkan koleksi tertentu atau karena adanya permintaan khusus dari publik

5) pameran keliling, yaitu pameran yang diselenggarakan secara bergiliran pada tempat-tempat yang berbeda dengan koleksi atau objek yang sama

6) pameran portabel, yaitu dengan mempertontonkan koleksi tertentu di tempattempat selain museum

7) pameran mobile, yaitu memamerkan koleksi secara berkeliling dengan kendaraan khusus (Carman, 2002: 120).

Berdasarkan tujuan dan gayanya, display dalam arkeologi publik antara lain meliput:

1) pameran dengan tujuan untuk pendidikan, orientasi pemilahan koleksi dan penataannya disusun secara sistematik

2) pameran dengan tujuan untuk hiburan, orientasi pemilahan koleksi dan penataannya disusun dan dikemas scera tematik

3) pameran dengan tujuan untuk membangkitkan emosi, terutama berkenaan dengan estetika dan romantika; orientasi pemilahan koleksi dan penataannya disusun sehingga memungkinkan publik berpartisipasi (participatory)

4) pameran dengan gaya responsif, yaitu pameran yang dirancang sedemikian rupa sehingga pintu koleksi atau alat peraga akan terbuka secara elektronik atau aktif secara otomatis ketika didekati oleh pengunjung

5) pameran dengan gaya interaktif, merupakan gaya pameran dengan menyediakan sejumlah rute yang dapat dipilih oleh pengunjung, sehingga pengunjung dapat 
membangun pemahaman tentang masa lalu secara mandiri sesuai dengan yang diinginkan dan dibutuhkan (Carman, 2002: 121).

Sementara itu, beberapa pesan arkeologis yang dapat dimuat dalam pameran menurut Carman antara lain meliputi:

1) makna lokal, arti penting arkeologi bagi publik setempat

2) nilai-nilai suberdaya arkeologis

3) arti penting perhatian publik dalan penelitian arkeologi dan konservasi

4) penjelasan bahwa sumberdaya arkeologi adalah seumberdaya yang tidak dapat diperbaharui

5) penjelasan tentang perbedaan antara ilmu arkeologi dengan pemburu harta karun atau barang rampasan (Carman, 2002: 122).

Lingkup arkeologi publik memang sangat luas, namun fokusnya tetap sama yaitu bagaimana "memanjakan" publik untuk kepentingan arkeologi. Memanjakan publik berarti juga menghadirkan berbagai informasi yang dihasilkan oleh arkeolog sesuai dengan kebutuhan mereka, sesuai dengan kerangka dan minat yang berkambang, termasuk ketika publik sedang demam karya seni fotografi "abnormal" yaitu fotografi infra merah. Apa itu fotografi infra merah?

\section{INFRARED PHOTOGRAPHY: Dari Ilmu menuju Seni}

\section{2.a Menuju Film Infra Merah}

Pada prinsipnya, fotografi yang selama ini kita kenal adalah pemindahan objek yang tertangkap mata karena mendapatkan cahaya, ke dalam media kertas melalui proses tertentu. Apa yang kita lihat seharusnya sama dengan apa yang tercetak, sebagaimana umumnya foto normal. Namun demikian ada batasan gelombang cahaya yang dapat tertangkap oleh mata, dan fotografi infra merah menembus batasan tersebut, khususnya gelombang cahaya di atas 700 nano meter.

Beberapa sumber di dunia maya menyebutkan bahwa mata manusia memiliki keterbatasan dalam melihat gelombang cahaya, yaitu objek dengan panjang gelombang 400 nanometer sampai 700 nanometer, yang kita kenal sebagai gelombang cahaya normal (merah, jingga, kuning, hijau, biru, dan ungu). Di bawah 
warna ungu adalah ultra violet (panjang gelombang kurang dari 400 nanometer), sedangkan di atas warna merah adalah infra merah (panjang gelombang lebih dari 700 nanometer).

Dalam dunia fotografi, film yang beredar di pasar diciptakan untuk dapat menangkap panjang gelombang normal, yaitu antara $400 \mathrm{~nm}-700 \mathrm{~nm}$. Ketika beberapa disiplin ilmu membutuhkan film yang dapatmenangkap panjang gelombang cahaya di atas $700 \mathrm{~nm}$, maka terciptalah "film infra merah". Panas adalah gelombang juga, walau panjangnya di atas merah, alias lebih panjang dari $700 \mathrm{~nm}$. Maka, sebenamya panas ini bisa dipotret. Dan inilah awal mula fotografi infra merah dimulai ketika para ilmuwan menciptakan film infra merah untuk tujuan ilmu. Sebagai contoh, foto buatan NASA menggambarkan bahwa panas yang dikeluarkan oleh pesawat yang tinggal landas terpusat pada beberapa tempat. Selain mesin, rupanya roda pendarat juga mengalami kenaikan suhu sangat tinggi. Gejala ini hanya dapat ditangkap oleh film inframerah karena panjang gelombang suhu tersebut di luar batas kemampuan mata manusia.

Penggemar fotografi kemudian memanfaatkan film ini sebagai uji coba estetik dan ternyata banyak digemari di kemudian hari, justru karena efek warna yang dihasilkan dianggap dramatis dan unik. Gejala yang paling banyak menjadi perhatian adalah over exposed objek daun dan ketidakterbatasan objek langit. Warna daun dengan film infra merah akan cenderung menampilkan citra putih atau perak, hal ini karena zat hijau daun memantulkan sinar infra merah, sehingga pada film infra merah akan terlihat over exposed. Warna langit akan cenderung lebih gelap karena film infra merah dapat menangkap gelombang cahaya di atas $700 \mathrm{~nm}$ yang ada di langit, meskipun diselimuti awan tipis. Secara estetika, efek seperti ini justru dikembangkan oleh para fotografer dan banyak dinikmati oleh para penggemar fotografi dan masyarakat luas. Oleh karena itu pada fotografi inframerah kehadiran matahari dan dedaunan pada pemandangan yang akan dipotret menjadi sangat pentingnya artinya.

Arbain Rambey menyatakan bahwa tidak banyak jenis film infra merah yang bisa didapatkan di pasaran. Di Indonesia, hanya film ILFORD SFX-200 yang 
secara resmi masuk di pasaran karena memang ada agennya di sini. Kodak HIE hanya masuk dalam jumlah sedikit secara tentengan sehingga sungguh sulit didapatkan. Film infra merah lain yaitu KONICA Infrared 750, AGFAAPX-200S dan KODAK Ektachrome Infrared IE (slide berwarna) belum pemah terlihat dijual di Indonesia.

Lalu, bagaimana dengan fotografi infra merah (IR) pada kamera digital?

\section{2.b IR untuk Kamera Digital}

Inti perbedaan kamera analog dengan kamera digital adalah perubahan penggunaan film yang digantikan dengan sensor; proses lainnya sama. Berkaitan dengan fotografi infra merah, maka film infra merah sebagaimana harus digunakan pada kamera analog, dalam hal ini digantikan dengan filter khusus yaitu filter infrared (IR). Namun demikian, kenyataannya dalam eksekusi maupun proses lanjutnya tidak sederhana, karena memerlukan berbagai persyaratan teknis dan non teknis.

Persyaratan teknis, misalnya untuk dapat menggunakan filter $\mathbb{R}$, kamera digital harus memiliki sensor yang dapat menangkap gelombang infra merah; fasilitas white balance dengan preset manual; fasilitas opsi eksekusi manual atau minimal semi manual (AV atau TV); tripod untuk stabilisasi pada saat eksekusi karena filter IR sangat pekat sehingga mengharuskan eksekusi dengan speed sangat rendah (1/8 detik atau lebih lambat); serta persyaratan lainnya. Dalam batas tertentu, pekatnya filter IR memang sering menimbulkan masalah baik komposisi, focusing, maupun stabilisasi dalam eksekusi.

Persyaratan teknis lainnya adalah pasca eksekusi, yaitu "normalisasi" foto yang hanya bisa dilakukan dengan komputer (digital darkroom). Beberapa fotografer memilih format RAW (tanpa kompresi) ketika memotret dengan menggunakan filter IR, meskipun dengan format JPG juga dapat dilakukan. Sementara itu format RAW hanya dapat dibaca oleh software produsen kameranya atau dengan photoshop versi $8.0 \mathrm{ke}$ atas (CS, CS2, dst). Digital darkroom dalam infrared photography memang menjadi "momok" bagi sebagian fotografer, namun bagi sebagian fotografer lain justru menilai di sini lah kreatifitas dan imajinasi secara total harus disalurkan. Mengapa? 
Fotografi infra merah adalah fotografi abnormal, sangat berbeda dengan versi color misalnya, yang normalnya dituntut untuk menghasilkan warna sesuai aslinya; dalam foto IR justru tidak ada batasan warna (color toned) maupun tuning lainnya (level, kontras, saturasi, dsb.) Kebebasan ini lah yang menjadi dorongan para fotografer dan penggemar fotografi untuk menekuni foto IR. Akibatnya, kita tidak akan melihat standar warna dan tuning pada setiap foto IR, objek yg sama dapat tampil dalam beberapa toned warna dan saturasi yang beragam. Toning foto $\mathbb{R}$ sangat tergantung pada keperluan dan tentu saja selera fotografer yang dalam beberapa hal didorong oleh selera publik.

Sementara itu, syarat non teknis berkaitan dengan beberapa hal yaitu objek, lokasi, dan waktu. Penggunaan filter IR yang berwarna merah pekat selain membutuhkan bukaan diafragma lebar dan speed sangat rendah, tentu saja membutuhkan intensitas cahaya yang lebih tinggi juga. Oleh karena itu, kehadiran matahari pada saat pemotretan sangat penting artinya dan hal ini hanya bisa dilakukan pada siang hari. Langit dan daun juga menjadi tuntutan agar foto $\mathbb{R}$ yang dihasilkan lebih tampak ke-IR-annya. Kedua objek ini akan sangat kontras karena daun akan menampilkan citra putih atau perak, sedangkan langit akan menampilkan nuansa gelap. POI (point of interset) atau objek bidikan yang berada pada dua konteks objek tersebut akan terkesan stand-out, sangat menonjol dan kontras. Sedangkan efek citra terang pada daun dan citra gelap pada langit secara psikologis akan menawarkan nuansa yang "mengejutkan", dramatis, dan estetik.

Untuk menghasilkan efek IR tersebut, pada kamera digital memang diperlukan filter khusus, yaitu filter infrared. Di pasaran, ada dua nama yang sangat akrab dengan para forografer di Indonesia yaitu R72 dan P007. R72 adalah filter infra merah produksi Hoya, sedangkan P007 merupakan filter infra merah produksi Cokin. Meskipun pekat, konon Cokin P007 sedikit lebih terang dibandingkan dengan Hoya R72. Perbedaan lain adalah Cokin P007 tidak dilengkapi dg ulir sehingga saat ekskusi harus ditempelkan pada lensa, ini memudahkan pada pengaturan komposisi tetapi kurang enak pada saat eksekusi, kecuali dilengkapi dengan alat tambahan berupa filter holder; Hoya R72 lebih pekat namun dilengkapi dengan ulir sehingga bisa menyatu dengan lensa, meskipun sulit dalam pengaturan 
komposisi namun lebih stabil dalam eksekusi dan tidakmemerlukan alat tambahan filter holder.

Meskipun agak rumit, namun fotografi inframerah terbukti telah membuka wacana baru dalăm dunia ilmu sekaligus seni, dan yang lebih terlihat adalah gejala "demam IR" yang memang menampilkan visual foto secara unik, dramatis, standout, dan ketidakterbatasan toning warna yang membawa fotografi IR sebagai sesuatu yang ditunggu oleh banyak kalangan. Bagaimana dengan dunia arkeologi?

\section{PUBLIK DAN PUBLIKASI ARKEOLOGI: Membaca "Pasar"}

Prasodjo (2004: 1) merangkum berbagai pengertian Arkeologi Publik yang paling tidak meliputi tiga definisi, yaitu:

1) Arkeologi Publik dipersamakan dengan Contract Archaeology atau Cultural Resources Management (CRM), yaitu berkaitan dengan pengelolaan sumberdaya budaya (arkeologi) yang mencakup segala hal yang biasa dilakukan dalam CRM, mulai dari konservasi sampai dengan masalah hukum/perundangan

2) Arkeologi Publik sebagai bidang kajian yang membahas mengenai hal yang berkaitan dengan bagaimana mempresentasikan hasil penelitian arkeologi kepada masyarakat. Cakupan dalam definisi ini lebih sempit karena yang paling utama dalam pengertian ini adalah masalah publikasi hasil penelitian arkeologi. Dalam hal ini, yang dimaksud dengan publikasi bukan hanya berarti penerbitan saja, tetapi melingkupi publikasi dalam bentuk yang lain, misalnya display museum, poster, film, sosialisasi arkeologi, dan sebagainya

3) Arkeologi Publik sebagai bidang ilmu arkeologi yang khusus menyoroti interaksi arkeologi dengan publik atau masyarakat luas. Interaksi tersebut dapat terjadi dalam dua arah, baik dari arkeologi ke publik maupun dari publik ke arkeologi.

Berkaitan dengan publik dan publikasi dalam banyak hal tidak terlepas dari masalah komunikasi. Dalam hal ini, awalnya audiens ditempatkan sebagai objek atau sasaran komunikasi, namun dengan kenyataan bahwa tidak setiap orang mampu memperhatikan media komunikasi, terdapat perbedaan dalam penerimaan, reaksi, dan sebagainya, maka terjadi perubahan orientasi dalam proses komunikasi dengan menempatkan audiens sebagai faktor yang sangat penting (Bauer, 1991: 
34). Hal ini antara lain ditunjukan oleh adanya tanggapan mereka dalam proses komunikasi sehingga dijadikan dasar untuk merencanakan proses informasi sebelum menyampaikannya kembali kepada audiens.

Secara lebih tegas, Bauer (1991: 35) menggambarkan bahwa perhatian khusus terhadap audiens muncul pada sekitar tahun 1940-an dengan dilatarbelakangi oleh dua hal, yaitu:

1) audiens ternyata memainkan peran aktif dalam memilih pesan komunikasi yang diinginkannya;

2) adanya reaksi yang berbeda yang diakibatkan oleh kelompok masyarakat berbeda terhadap pesan komunikasi yang sama.

Mirip dengan pandangan Bauer, De Fleur (1991: 5) menjelaskan bahwa komunikasi tidak terlepas dari dasar-dasar teori psikologi. Dalam hal ini setiap individu dianggap memiliki kepribadian masing-masing yang akan mempengaruhi perilaku mereka dalam merianggapi sesuatu. Audiens dari suatu medium komunikasi bukanlah suatu kelompokmonolitis yang anggota-anggotanya senantiasa mempunyai tanggapan yang sama terhadap isi medium. Oleh karena itu, pengaruh media terhadap individu akan berbeda satu sama lain yang disebabkan adanya perbedaan psikologi antarindividu.

Berkaitan dengan pemasyarakat hasil penelitian dan kegiatan kearkeologian, tentu saja peran publik tidak dapat diremehkan. Selain adanya kemajemukan, tingkat daya tangkap dan ketertarikan juga menjadi hal yang perlu "dibaca" agar pesan yang akan disampaikan dapat efektif. Fotografi infra merah yang sedang melanda masyarakat dewasa ini dapat menjadi peluang untuk menembus salah satu "pangsa" dalam kaitannya dengan publikasi arkeologis. Hal lain yang dapat melandasi pemanfaatan infrared photography dalam pemasayrakatan arkeologis adalah 1) fotografi infra merah dapat digunakan untuk menampilkan secara lebih menonjol suatu objek arkeologis, 2) efek unik yang dihasilkan dapat menjadi daya tarik tersendiri untuk mendorong apresiasi publik terhadap dunia arkeologi, 3) dibandingkan foto normal, foto IR cenderung lebih "laku" dan diminati pada berbagai kesempatan publikasi. 
Di sisi lain, dalam arekologi publik, presentasi dapat dilakukan melalui beberapa cara dan media, antara lain melalui display. Berkaitan dengan hal tersebut, Carman (2002: 199-122) menguraikan tentang bentuk-bentuk display, tujuan dan 'gaya' display, serta makna dan pesan arkeologis yang dimuat dalam display tersebut, sebagaimana diuraikan pada awal tulisan ini. Fotografi infra merah dalam batasan tertentu dianggap sangat cocok untuk menunjang display ini, meskipun untuk keperluan publikasi yang lain juga dapat dimanfaatkan, seperti slideshow, CD-I, video digital, dan produk multi media yang lain, dan bahkan juga untuk media cetak seperti album penelitian, leaflet, booklet, poster, dsb.

\section{PENUTUP: Membuka Cakrawala Publikasi Arkeologis}

Dalam kerangka publikasi, pemanfaatan fotografi infra merah termasuk dalam kategori publikasi kemasan visual; di samping kemasan tulis dan kemasan lisan. Ekstensifikasi dan intensifikasi masing-masing kemasan tidak mempunyai batas, selama masih berlandaskan aspek akademis, dan yang lebih penting saat ini adalah sesuai dengan perkembangan teknologi yang mendorong perkembangan pula pada perubahan orientasi dan apresiasi pada setiap jenis publikasi.

Fotografi infra merah hanyalah salah satu dari sekian banyak cara untuk menampilkan objek secara artistik dan menarik. Lebih luas lagi, fotografi secara

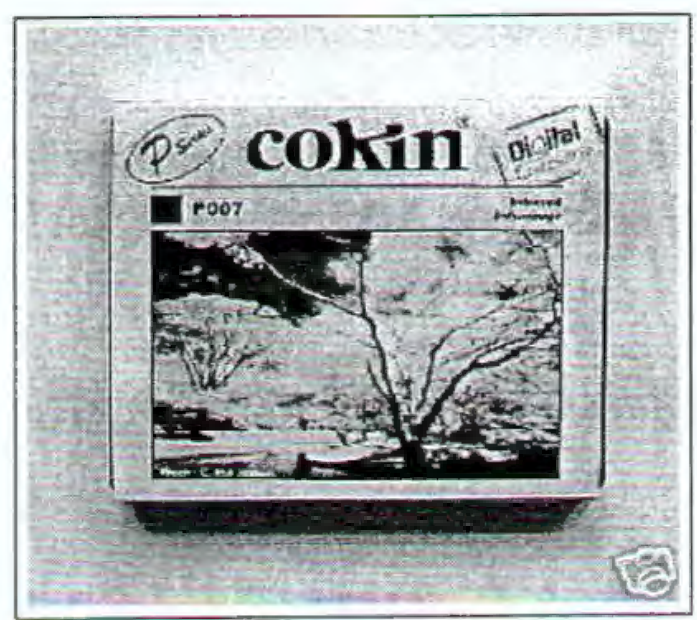

Filter IR produksi Cokin, seri P007

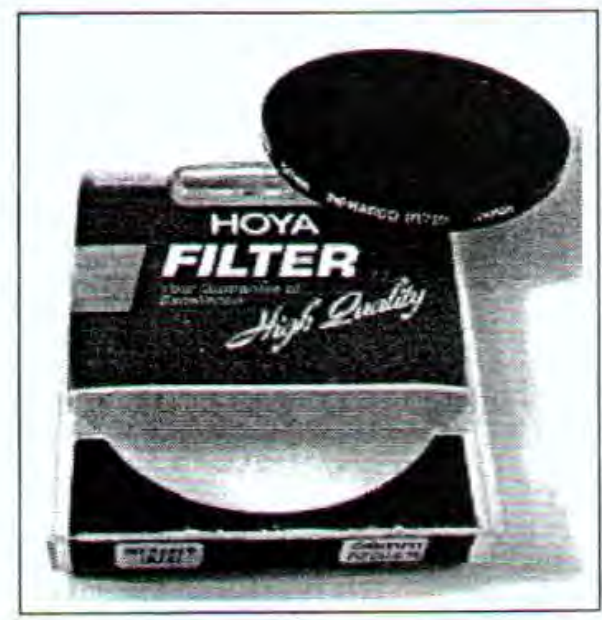

Filter IR produksi Hoya, seri R72 
umum merupakan media yang paling sering digunakan oleh berbagai pihak dalam mengkomunikasikan suatu kondisi kepada publik, termasuk kalangan arkeologi. Barangkali, sudah saatnya arkeolog untuk mencoba memanfaatkan infrared photography untuk pemasyarakatan arkeologis, sebagai upaya membuka cakrawala publikasi arkeologis

\section{DAFTAR PUSTAKA}

Bauer, Raymond A. 1991. “Tentang Audience”. Peranan Komunikasi Massa dalam Pembangunan. Eduard Depari dan Colin MacAndrews (eds.). Yogyakarta: Gadjah Mada University Press, pp. 33-43.

Carman, John. 2002. Archaeology and Heritage, an Introduction. London: Continuum.

De Fleur, Melvin. 1991. “Teori-teori Komunikasi Massa Kontemporer”. Peranan Komunikasi Massa dalam Pembangunan. Eduard Depari dan Colin MacAndrews (eds.). Yogyakarta: Gadjah Mada University Press, pp. 3-15.

Iseminger, William R. 1997. "Public Archaeology at Cahokia" dalam Presenting Archaeology to the Public. John H. Jameson Jr. (ed.). California: Altamira Press. pp.147-155.

Prasodjo, Tjahyono. 2004. Arkeologi Publik. Makalah disampaikan dalam rangka Pelatihan Pengelolaan Sumberdaya Arkeologi Tingkat Dasar di Trowulan.

Infrared Basics for Digital Photographers <http://www.cliffshade.com/ dpfwiw/ir.htm>

Infrared Photos $<$ http://satirist.org/photo/ir/ $>$

Kleptography $<$ http://www.kleptography.com/s-gallery-ir.htm $>$ 


\section{BEBERAPA CONTOH FOTO COLOR vS IR}
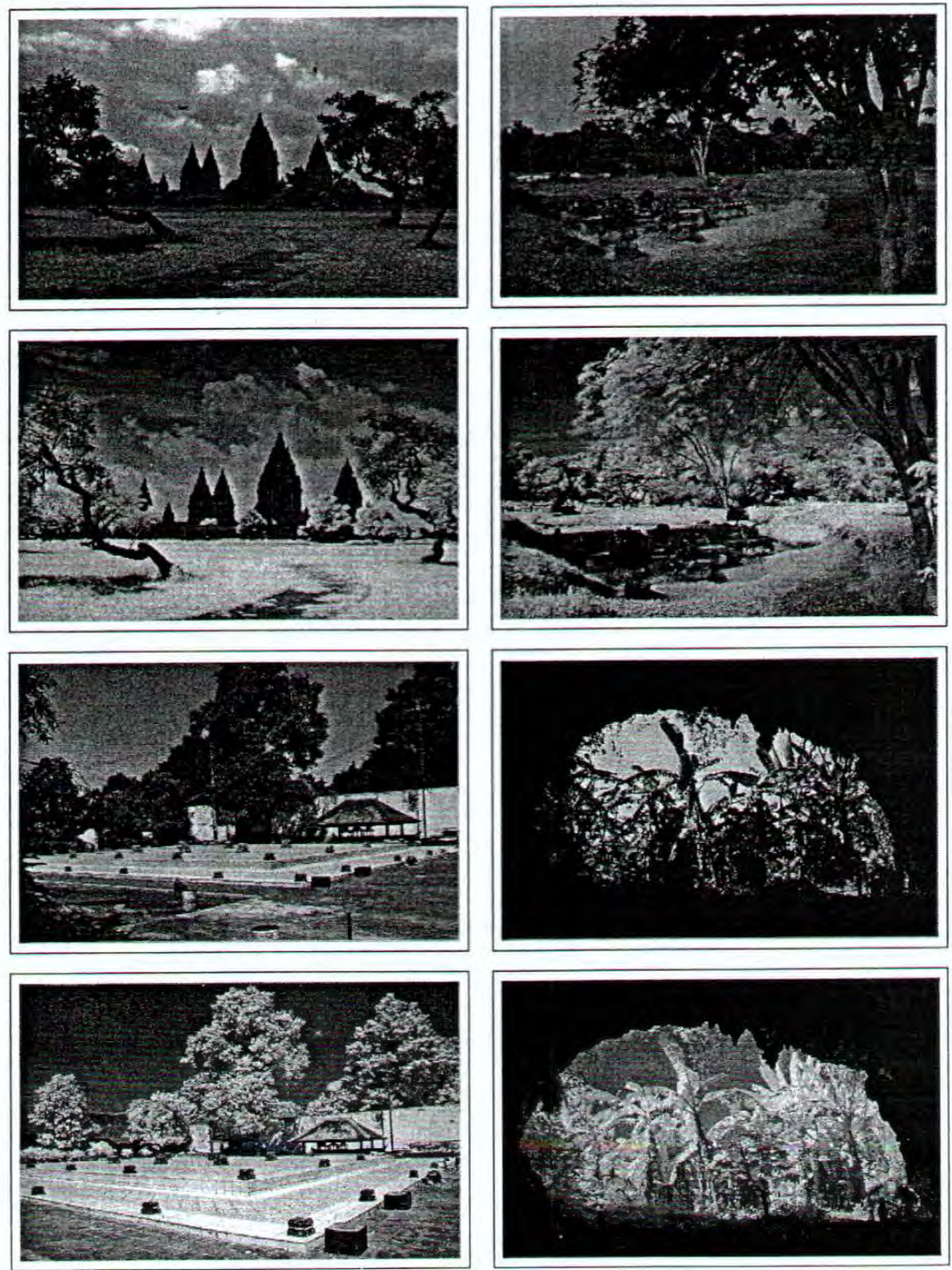

Berkala Arkeologi Tafun XXVI Edisi No. 2 /November 2006 

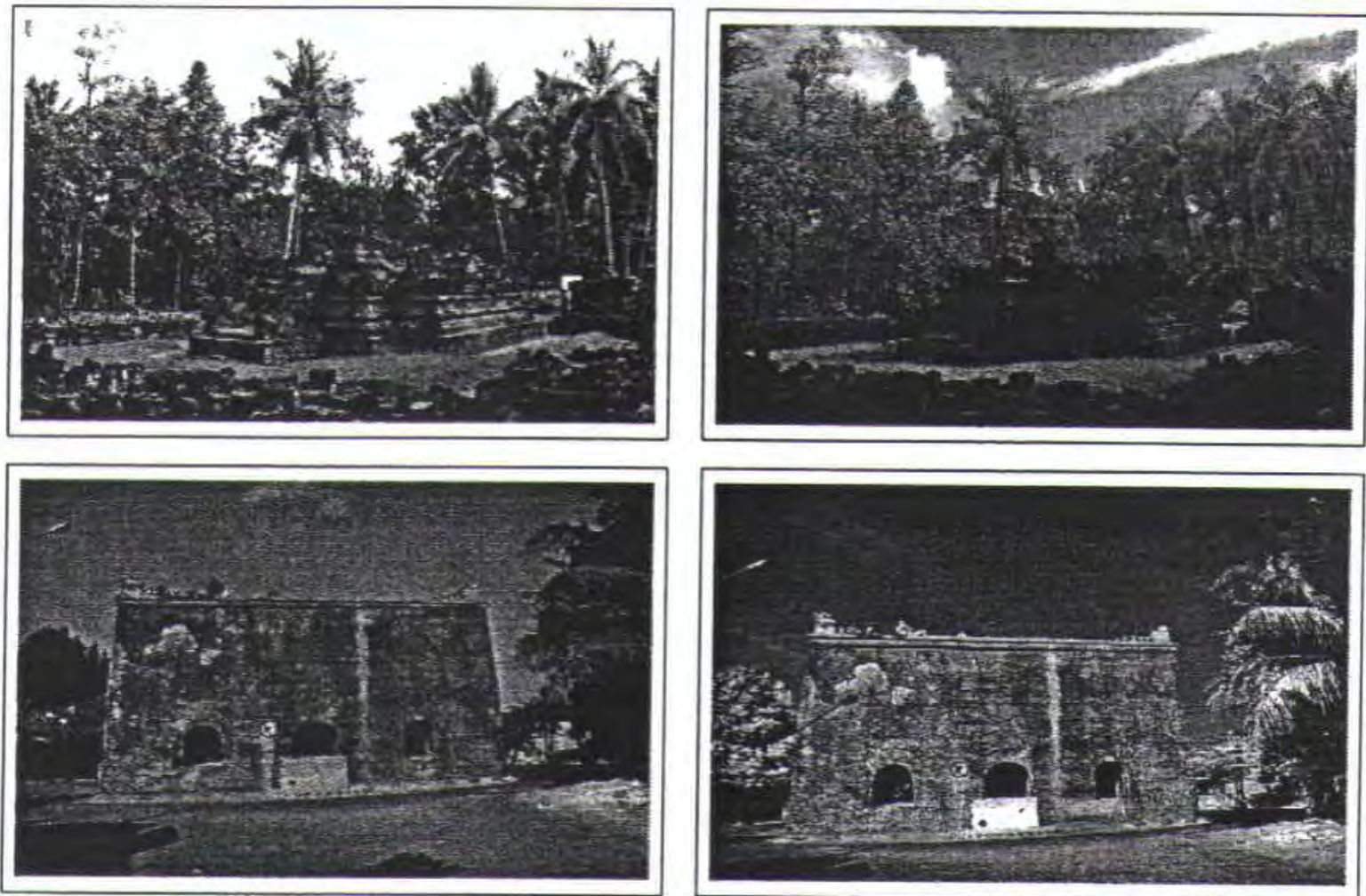